\title{
Synthetic Oil-Spills Decontamination by Using Sawdust and Activated Carbon from Aloe vera as Absorbents
}

\author{
Elie Meez ${ }^{1}$, Ahmad Hosseini-Bandegharaei ${ }^{2}{ }^{\mathbb{D}}$, Abbas Rahdar ${ }^{3}$, Anna Thysiadou ${ }^{1,4}$, \\ Kostas A. Matis ${ }^{5}$ (D), George Z. Kyzas ${ }^{1, *}$ \\ 1 Department of Chemistry, International Hellenic University, Kavala 65404, Greece; eliemouez@ gmail.com (E.M.); \\ 2 Department of Environmental Health Engineering, Faculty of Health, Sabzevar University of Medical Sciences, Sabzevar, \\ Iran; ahoseinib@yahoo.com (A.H.-B.); \\ 3 Department of Physics, University of Zabol, Zabol 98613-35856, Iran; a.rahdar@uoz.ac.ir (A.R.); \\ 4 Kavala Port Authority S.A., Kavala 65403, Greece; thysiadou@ hotmail.com (A.T.); \\ 5 Department of Chemistry, Aristotle University of Thessaloniki, Thessaloniki, GR-541 24, Greece; kamatis@hem.auth.gr \\ (K.A.M.); \\ * Correspondence: kyzas@ @ chem.ihu.gr (G.Z.K.);
}

Scopus Author ID 17345938100

Received: 20.11.2020; Revised: 14.12.2020; Accepted: 16.12.2020; Published: 18.12.2020

\begin{abstract}
The main objective of this work is to try to find potential novel absorbents that could be used for oil spill cleanup. The swelling properties of poplar sawdust were investigated in order to predict its behavior in adsorption with two types of oils (i) diesel and (ii) heating oil. The sorption experiments for sawdust on both diesel and heating oil showed that the prediction obtained by the swelling experiments were correct, and the sawdust exerted good sorption characteristics for both oils. The second part of the experiment focused on synthesizing activated carbon from Aloe vera to check its potential for oil removal. Through BET analysis, characterization showed the high surface area, and FTIR analysis pointed out some possible functional groups. The absorption experiments showed moderate sorption capacity of this material based on diesel experiments and good sorption results with heating oil.
\end{abstract}

Keywords: Aloe vera; activated carbon; sawdust; absorption, oil-spills.

(C) 2020 by the authors. This article is an open-access article distributed under the terms and conditions of the Creative Commons Attribution (CC BY) license (https://creativecommons.org/licenses/by/4.0/).

\section{Introduction}

Oil spills are regrettably common around the world: they originate in oil platforms (such as the big disaster in the Gulf of Mexico a decade ago), refineries or oil tankers that have an accident (or that 'clean' their tanks in the ocean) [1,2]. The aforementioned 2010 rig explosion, which killed 11 workers and sent oil spewing into the gulf for 87 days, triggered one of the worst environmental disasters in US history, according to the newspaper; it released $206 \mathrm{~m}$ gallons of oil from the well, affecting wildlife and water-quality along hundreds of miles of the coastline. Hence, global environmental problems are becoming more and more acute.

Certainly, one of the promising techniques applied for the decontamination of wastewaters constitutes adsorption; the potential of nanomaterials as sorbents and their many advances were discussed in detail [3]. Activated carbons (of various porosity) are among the suitable adsorbents because of their good sorption capacity [4]. Their use has often been prohibited due to their relatively high cost, regeneration problems, and low selectivity. Adsorption isotherms, thermodynamics, kinetics of the process, and different characterization analytical techniques have been discussed. The composition of sorbents in a composite (when 
used as such) enhanced both the hydrophobic and oleophilic properties. As a result, a more effective removal of diesel and oil from the water surface was achieved [5].

In general, different physicochemical processes have been examined for oily wastes, including coagulation and flotation [6], being effective as a liquid/liquid separation technique for oil-water emulsions. In the latter, when electrolysis was applied for the generation of the necessary bubble and due mainly to the low space requirement, it was tested for bilge water and effluent treatment on a ship, too [7]. Often for oil spill remediation, chemical dispersants have been applied, also in situ burning and mechanical removal. However, the augmented toxicity and poor biodegradability of dispersants have created the necessity for replacing the dispersants used, as reported [8].

The thermochemical modification of lignocellulosic waste biomass, an abandoned agro-industrial by-product (pine sawdust was included there), was said to provide relatively low-cost adsorbents with increased sorption capacity and biodegradability, appropriate for the removal of chemicals, heavy metals, and oil spills from aquatic media [9-15]. Elsewhere [16], chemically and biologically pretreated rice husk cellulosic sorbents were investigated for oil sorption capacities. Natural sorbent materials have practical advantages for the oil spill cleanup, their low-cost, feasibility for real-life applications, and environmental adaptability [17].

Aloe vera is a succulent plant species (according to Wikipedia), found in many consumer products, including beverages, skin lotion, cosmetics, or ointments for minor burns and sunburns. Noting that few publications deal with its present application - i.e., a triazene azo dye was removed from contaminated wastewater samples using a green adsorbent recycled from Aloe vera leaves waste [18]. Many researchers have studied the biosorption (i.e., the process that uses dead biomass) of different pollutants [19-25]; microorganisms' ability to remove metal ions, for instance, is a known phenomenon. Efforts were conducted to isolate bacteria strains from metal-polluted strains (mining and industrial areas) and investigated them as possible effective biosorbents.

Sawdust, natural cellulosic material and easily available by-product in the timber and paper industry, is regarded as a relatively dominant material among all kinds of adsorbents thanks to its low-cost advantages, eco-friendly, and low density [26]. Biosurfactants, obtained from several microorganisms, have also received attention as emulsifiers and oil recovery agents; so, their use to modify lignocellulose sawdust for oil spill cleanup was evaluated; and the biodegradation potential was evaluated after 5 days [27]. Certain sorbent materials showed limitations, especially in the presence of waves and wind [28]. A synthesis was reported of various organic-inorganic hybrid matrices with magnetic properties, obtained in the form of powders and membranes [29]; biomass wastes were applied to form the organic phase, including sawdust.

\section{Materials and Methods}

\subsection{Materials.}

The types of oils to be tested for the sorption experiments were diesel oil and heating oil (Figure 1). Aloe was harvested from a local garden. 


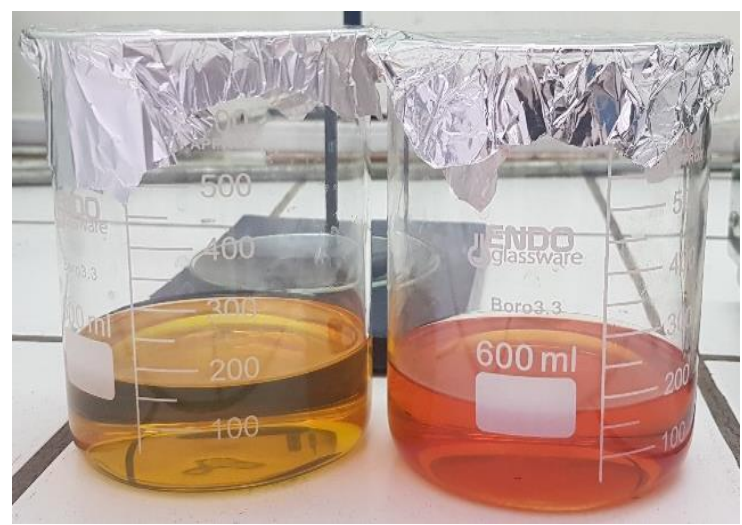

Figure 1. Tested oils in sorption experiments: Diesel oil (yellow - left) and Heating oil (orange - right).

\subsection{Absorption experiments.}

To proceed with the sorption experiments, which aim to test the sorption capacity of the chosen synthesized compound based on Aloe vera towards both diesel oil and heating oil, several previous steps and procedures had to be considered and achieved.

\subsubsection{Sawdust.}

The first step to be implemented was to check the swelling properties of poplar sawdust that was provided locally with deionized water. This step consisted mainly of inputting a certain amount of poplar sawdust within conical flasks filled with deionized water at a stable temperature for a certain time to be recovered later and reweighed. The method agreed upon for implication was to pour $50 \mathrm{~mL}$ of deionized water in $200 \mathrm{~mL}$ conical flasks and then add around $1 \mathrm{~g}$ of poplar sawdust for each conical flask, which will be transferred to a water bath in order to stabilize the whole experiment under a temperature of $25^{\circ} \mathrm{C}$. In the experiments, a total of 10 conical flasks was placed in the water bath containing the specified amount of poplar sawdust and volume of deionized water. Each flask was corresponding to a certain time allowed for the sorption of the deionized water particles onto the poplar sawdust, which is $5,10,20,30$, and $45 \mathrm{~min}$ in addition to $1,1.5,2,3,6$, and $24 \mathrm{~h}$ to reach a total of 10 different sorption periods corresponding to the 10 conical flasks used. To keep the bulk of the poplar sawdust together as much as possible, especially when contacted with the deionized water, $1 \mathrm{~g}$ of poplar sawdust was weighed and then put into a filter paper sealed carefully, thus resembling a teabag. The material's weight to be introduced to the conical flask filled with deionized water was then recorded. It included both the weight of poplar sawdust and the filter paper before its installation into the proper conical flask for the swelling experiment. All of the sorption experiments calculations, including the swelling experiments, in order to obtain the sorption capacity, are based on the following equation (Eq. 1):

$$
S=\frac{\frac{m i-m f}{m i}}{m s}
$$

where $m_{i}$ is the initial mass of the adsorbate in $(\mathrm{g}), m_{f}$ is the final mass of the adsorbate, and $\mathrm{m} s$ is the mass of the sorbent used in $(\mathrm{g})$

This procedure was done for all of the respective flasks. Another reason for filling the poplar sawdust masses into filter papers was to remove the conical flask when the experiment is over easier since the recovery of the filter paper containing the now popular sawdust and the additional mass of water is relatively easier than trying to recover stranded sawdust from the conical flask which will result in loss of poplar sawdust mass and hence cause inaccuracy in 
the results obtained. After an experiment is finished, the poplar sawdust is recuperated from the conical flask and laid on a filter paper to naturally dry, usually for a period of 3 days, in order to make sure that the deionized water that was absorbed by the filter paper while extraction of sawdust was fully dried and the only extra amount of water that remains is the one present within the cells of poplar sawdust. After drying, the filter paper containing now the poplar sawdust and its additional water content is weighted again in order to determine the new mass of poplar sawdust, therefore, deducing the percentage of swelling of poplar sawdust. The reason why swelling experiments were conducted on poplar sawdust in this experiment or on any other compound subjected to sorption experiments is to understand the compound's morphological structure in question. From the results acquired from the swelling experiments, graphs will be constructed, and from the plotted points of these graphs representing the swelling capacity of poplar sawdust concerning time, a clear understanding of the structure of the compound in an investigation will be provided, which leads to a better understanding of the behavior of the structure of the compound regarding sorption of certain elements, therefore, allowing a further modification of the structure of the compound investigated in order to achieve better sorption characteristics.

After finishing with the swelling experiments, the whole process's second step begins also involving the poplar sawdust. This step was concluded after several literature reviews stating different sawdust types as potential cleanup processors for oil spills; therefore, sorption experiments of poplar sawdust with both heating oil and Diesel oil were conducted. This experiment's basic steps are relatively similar to the ones adopted for the swelling experiments with a small number of modifications. For instance, 10 conical flasks of a volume of $200 \mathrm{~mL}$ representing 10 different settling time will also be used where oil will be poured. However, instead of using $1 \mathrm{~g}$ of sawdust as previously done with the swelling experiments regarding sawdust with deionized water, a reduced quantity of $0.5 \mathrm{~g}$ of sawdust will be used while experimenting with oil due to the lack of sawdust availability and hence reducing the quantity of poplar sawdust used will ensure that the remaining quantities of poplar sawdust will be enough to proceed with the whole sorption experiments relating poplar sawdust with both diesel and heating oils. Naturally, since the amount of poplar sawdust was reduced to $50 \%$, it is necessary to keep the calculations proportional and decrease the volume of oil used in the experiment, whether it is diesel oil or heating oil, by $50 \%$. Therefore the amount of oil that will be poured into the conical flasks will be reduced to $25 \mathrm{~mL}$.

In other words, 10 conical flasks will be used in which $25 \mathrm{~mL}$ of diesel oil as a first step will be poured in each flask, and $0.5 \mathrm{~g}$ of poplar sawdust will be introduced to create the wanted combination. After being weighted, poplar sawdust will be enveloped with a filter paper and weighted again, where a new weight will be recorded for the same purposes that were explained for the swelling experiments. Each conical flask corresponding to a certain contact time ranging from 5 min until $24 \mathrm{~h}$ and containing the respective amounts of poplar sawdust and diesel oil will be sealed using aluminum foil and then placed in a water bath with a stable temperature of $25^{\circ} \mathrm{C}$. After each conical flask's respective contact time has been achieved, the filter paper containing both poplar sawdust and the retained diesel oil will be recovered and placed on filter papers to dry naturally for 3 consecutive days to make sure that no more traces of oil are present. After the samples are dehydrated, the filter paper bearing with it now the poplar sawdust and the appropriate amount of diesel oil retained will be weighed in order to finally deduce the sorption capacity of sawdust in respect to diesel oil and the respective contact time related to it. It should be noted that this sorption experiment is also repeated 2 times to avoid human 
errors; thus, the outcome for each contact time will be deduced from the average of the three batches prepared to obtain a sorption capacity that is as close as possible to the reality.

The procedure adopted for diesel oil's sorption with poplar sawdust will be repeated the same way but this time while using heating oil instead of diesel oil. Still, in the third step of the full experimentation, the sorption capacity of poplar sawdust for heating oil will be evaluated by pouring $25 \mathrm{~mL}$ of heating into a $200 \mathrm{~mL}$ conical flask in 10 different batches, with each batch corresponding to a specific settling time between poplar sawdust and heating oil for times ranging from 5 min up to 24 hours and the heating oil in each conical flask would be mixed with $0.5 \mathrm{~g}$ of poplar sawdust covered with a filter paper as the steps done previously. After that, the amount of the sawdust in addition to the filter paper, have been weighted. After the settling time has been reached for each conical flask, the sawdust with the retained heating oil is recovered and left on filter papers to dry naturally for three full days, after which the new mass of the filter paper collected will be weighed again in order to determine the final sorption capacity of sawdust regarding heating oil with the implementation of three times of the experiment in order to avoid possible stranded results and the results adopted for the sorption experiment of sawdust with heating oil will be the average of the three results collected from the experiment.

In a summary of the sorption experiments related to the poplar sawdust, all the steps are mainly the same as the swelling experimentations, except a reduction in the amounts of poplar sawdust and the two types of oil used. Moreover, the experimentations of poplar sawdust with both oil types were repeated two more times for human error reduction. The average of the three results was adopted as the outcome. The results will then be plotted into scatter points, forming a graph representing the sorption capacity of sawdust for both types of oil used in the experiment concerning contact time. These graphs will be created using the Origin 8.0 software, and this software was adapted to get more precise graphs.

\subsubsection{Activated carbon from Aloe vera.}

After the end of the swelling and sorption experiments, which both involve the use of poplar sawdust, the focus is then shifted to the third step, which is considered a very important step and is based around the main aim of this research and this step circles around the Aloe vera and the process of synthesizing the final product. Noting that Aloe vera will not be used in the sorption experiments as it is found naturally. However, certain modifications will be implemented to improve the morphological structure of the Aloe vera, which might lead to better sorption capabilities. Aloe vera was harvested from a local farm and then washed with deionized water for a total of 1 day and a half to remove the impurities that were stuck on the surface of Aloe vera.

In the washing process, Aloe vera leaves were cut into small pieces. Usually, the weight of Aloe vera that is considered acceptable to form a batch is around 80 grams and put in a 500 $\mathrm{mL}$ beaker were half a liter of deionized water was poured alongside a magnetic stirrer, after that the proper beaker now containing the small pieces of Aloe vera and the deionized water will be sealed using an aluminum foil in order to prevent some reacting agents to evaporatefrom evaporating from the beaker in case they were present and cause a potential threat in the laboratory where the experiment is being conducted. The whole beaker is put on the stirring equipment. The washing process starts as the deionized water is washing the Aloe vera pieces via stirring for 1.5 days. After the washing process is finished, the Aloe vera pieces are filtered from the deionized water and put on filter papers in order for the deionized water to dry 
naturally and allow the surface of the Aloe vera to be dried even if slightly and for a period of time usually set for a couple of hours ( 2 to 3 hours). After the Aloe vera have dried naturally for a short period, the Aloe vera is then collected and put in porcelain plates then sealed again with aluminum foil to be introduced to an oven where the drying process will be operated at a temperature of $110^{\circ} \mathrm{C}$ for 12 hours in order to remove the water molecules that are still present on the surface of the pieces of Aloe vera alongside some other component that could become vaporized at the specified temperature hence further purifying the Aloe vera pieces.

After the drying process, the Aloe vera will be subjected to a surface enhancement phase, which will introduce potassium hydroxide $(\mathrm{KOH})$ into the Aloe vera's surface. Potassium hydroxide was selected because literature provided some information about the use of chemicals to improve the Aloe vera's surface, which suggested the use of an acid or a base, which is why potassium hydroxide (base), which is readily available in the laboratory, was chosen. A concentration of $1 \mathrm{M}$ of $\mathrm{KOH}$ was adopted for the surface improvement process. Calculations were made in order to provide the proper proportions of materials needed for this step. This calculation concluded that a reasonable amount of potassium hydroxide to be used with Aloe vera would be around $5.611 \mathrm{~g}$. This amount of $\mathrm{KOH}$ will be used with an appropriate volume of $100 \mathrm{~mL}$ of deionized water to reach a $1 \mathrm{M} \mathrm{KOH}$ solution.

After the calculations have been set, the dried Aloe vera is put in a $500 \mathrm{~mL}$ beaker with a magnetic stirrer where $100 \mathrm{~mL}$ of deionized water will be poured, after which the specific amount of potassium hydroxide will be added slowly, while the beaker has been set on the stirrer to ensure efficient mixing of the potassium hydroxide and creation of the solution. The beaker is then covered with aluminum foil for safety reasons because the reaction of potassium hydroxide is exothermic. The mixing process is conducted for $12 \mathrm{~h}$ to make sure that the maximum adaptation of basic ions on the surface of Aloe has been achieved.

When the mixing process ends, Aloe vera is separated from the solution of $1 \mathrm{M}$ potassium hydroxide and settled on filter papers in order to dry naturally for around 2 hours. Now that the Aloe vera is slightly dried and ready to be transported, another drying step is performed by introducing the improved newly enhanced Aloe pieces into the oven for drying at a temperature of $110^{\circ} \mathrm{C}$ for a period of 12 hours. Pyrolysis is the final step of the syncretization of the desired Aloe vera compound for the sorption experiments. It involves reintroducing the newly dried (for the second time) Aloe in the oven at a certain temperature $\left(100^{\circ} \mathrm{C}\right.$ or $\left.120^{\circ} \mathrm{C}\right)$ until a temperature of $500 \mathrm{OC}$ is reached. This is done by incrementing the temperature by $20^{\circ} \mathrm{C}$ every 5 minutes. While the pyrolysis is ongoing and when the temperature is nearing its final target $\left(500{ }^{\circ} \mathrm{C}\right)$, an input of nitrogen is introduced to the oven to finalize the procedure. The pyrolysis is conducted at these stable conditions for three hours, after which the compound residing in the oven is recovered. The oven is shut down to finally acquire the desired product that will be used for the sorption experiments and which is an activated carbonbased on Aloe vera and improved by potassium hydroxide.

Now that the proposed activated carbon based on Aloe vera is finally synthesized, it is time to initiate Aloe's sorption experiments. Unfortunately, the yield of aloe leaves is very low, meaning that fair amounts of aloe leaves will be needed to create sufficient activated compounds for the sorption experiments $(80 \mathrm{~g}$ of aloe pieces will roughly yield after the whole synthesis process around $1 \mathrm{~g}$ of the activated compound); therefore it is expected to repeat the synthesis process a few more times to ensure that there is enough quantity of activated Aloe vera to perform the whole sorption experiments on the different types of oils to be used, the reexperimentations and the characterization processes. The process of testing the sorption 
capacity of the newly formed compound will be conducted with both diesel oil and heating oil is typically the same procedure underwent by poplar sawdust in its sorption experiments.

The activated Aloe vera will be provided for testing in powder form. Therefore, it is very important to implement extreme caution when dealing with the compound in order to prevent loss of materials; moreover, since the yield of the synthesized product is very low, it is advisable to lower the numbers of Aloe vera activated compound when used in the sorption experiments to ensure enough quantities for the whole process. So, the number of conical flasks will be set again to 10, representing different contact times with a time range between 5 minutes until 1 day; however, the amount of activated Aloe that will be used in each flask will be reduced to $0.25 \mathrm{~g}$ in comparison to the $0.5 \mathrm{~g}$ of sawdust that was used for sorption experiments and $1 \mathrm{~g}$ of sawdust for the swelling experiments. In order to be able to decrease the amount of activated Aloe in the experiment and keep proportional measurements, the volume of oil to be used should be divided in half in parallel to the reduction of the amount of sorbent by half. Thus, $12.5 \mathrm{~mL}$ of oil (heating or diesel oil) will be poured in each conical flask.

Just like the previous steps done with poplar sawdust, and since the activated Aloe is in its powder form, caution must be adopted when handling this compound, so it was decided to envelop the necessary quantity $(0.25 \mathrm{~g}$ for each conical flask) with a filter paper and seal it correct to prevent mass loss. Then the sealed filter paper containing the appropriate quantity of activated Aloe will be weighted for each conical flask and then put in the conical flask were $12.5 \mathrm{~mL}$ of diesel oil will be poured in each conical flask and then sealed with an aluminum foil and settled in a water bath for a stable temperature of $25^{\circ} \mathrm{C}$ until the respective contact time is reached. After that, the wetted filter paper containing now both the activated Aloe and the diesel oil is recovered from the conical flask and left on a filter paper to settle and dry naturally for approximately three full days, after which the envelope of the dried filter paper in addition to its content (activated Aloe) will be weighted, and the result will be recorded. This will be done for each conical flask or each contact time. Each result will transform into a point where these points will be forming a graph representing the sorption capacity of activated Aloe versus the contact time. This graph will be illustrated via Origin 8.0 software. It gives a better understanding of the performance of activated Aloe in the sorption of diesel oil.

The remaining part of the sorption experiment will evaluate the enhanced Aloe vera's sorption capacity with diesel oil. The same steps that have been applied for the sorption of diesel oil into activated Aloe will be applied exactly in the same way, with the only difference being replacing diesel oil with heating oil and while retaining the same procedures and measurements that were adapted specifically with the experiment involving diesel oil and activated Aloe ( $0.25 \mathrm{~g}$ of activated Aloe and $25 \mathrm{~mL}$ of heating oil). After the complete setup of the experiment's full batch, the conical flasks bearing activated Aloe and heating oil will be settled in the water bath for the appropriate contact time to be then recovered and dried naturally for three days again and weighted after this period for final mass evaluation.

After the final calculations are made, graphs relating the sorption capacity of heating oil into the activated Aloe will be illustrated using the Origin software for comparison to verify the possibility of activated Aloe being a good sorbent for the heating oil. This section covered in details the whole procedure underwent in this research with a special emphasis on the recipe prepared in order to synthesize the final product, which is the activated Aloe in order to be used for sorption experiments with both diesel and heating oil while providing specific steps and procedures to ensure that the correct methods are implied with minimal error. The next section will be providing details about the characterizations part, including the equipment that has been 
used for the characterization of the activated Aloe vera, with some brief explanations surrounding the functioning of this equipment.

\subsection{Characetrization.}

FTIR analysis was used to characterize the functional groups of materials. The laboratory equipment used to conduct the FTIR analysis was the Frontier MIR/FIR spectrometer (PerkinElmer). This system possesses many advantages. It is a single optimized system with an automatic reconfiguration that allows the shifting between the samples without the need for a manual process. The temperature at which the FTIR spectrometer could operate with no problem is set by the company to between 5 and $40{ }^{\circ} \mathrm{C}$; moreover, the spectrum 10 software runs on this equipment and allows the receipt of optimized results from the analysis.

BET analysis is another characterization process that circles around the BrunauerEmmet-Teller (BET) equation, which is used to determine the surface area of the tested compound. Usually, the compound set for BET analysis is in the form of a solid, but the material in its gaseous phase could also be used. The BET method usually relies on nitrogen adsorption at a temperature of $77 \mathrm{~K}$. After the process is done, the plot will present a graph that will resemble one of six possible adsorption isotherms according to the IUPAC classification. The NOVA 4200a (Quantocrome instruments) was available to assess the activated Aloe's specific surface area. This equipment is not only used for analyzing surface areas but also for porosity analysis. It possesses two chambers, one for degasification and the other for the analysis, where 4 samples can be input for analysis simultaneously.

\section{Results and Discussion}

\subsection{Characterization.}

\subsubsection{FTIR analysis.}

Figure 2 shows the FTIR (Fourier transform Infrared) spectroscopy that was performed on the activated Aloe in the hopes of determining whether functional groups that help increase that adsorption process are present and their types. Usually, when interpreting an FTIR spectrum, the focus is on the wavelengths ranging between $1500 \mathrm{~cm}^{-1}$ and $3000 \mathrm{~cm}^{-1}$. This is where the functional groups will be present. Moreover, a higher peak in FTIR means that the compound or element has absorbed a higher infrared quantity. Elements shown for a wavelength surpassing $1500 \mathrm{~cm}-1$ are considered fingerprints even though some functional groups could be absorbed in this area; however, it cannot be granted confirmation that these functional groups can correctly assess the compound's composition tested. The fingerprint's role is to give information on what's going on within a molecule rather than showing the functional groups contained in the compound subjected to the spectroscopy.

According to Figure 2, the peak shown at a wavelength of $3124.8 \mathrm{~cm}^{-1}$ indicates the presence of an alcohol group (O-H stretching), the peak at $1636.08 \mathrm{~cm}^{-1}$ could be attributed to a $\mathrm{C}=\mathrm{O}$ stretching or a $\mathrm{C}=\mathrm{C}$ stretching. However, most probably, this peak belongs to a $\mathrm{C}=\mathrm{O}$ stretching since it is broader, while a $\mathrm{C}=\mathrm{C}$ stretching usually has a sharper peak. Also, the visualization of a "teeth-like" formation ranging from the values of $1760 \mathrm{~cm}^{-1}$ until $1730 \mathrm{~cm}^{-1}$ could be a sign of the presence of aromatics in the activated Aloe. At $2483 \mathrm{~cm}^{-1}$ until 2203.74 $\mathrm{cm}^{-1}$, a small series of perturbations can be seen on the figure, indicating small noises. However, a small peak forming at $2483 \mathrm{~cm}-1$ has a slight chance of signaling the presence of 
formaldehyde. However, it is tricky to detect such compounds a small potential of formaldehyde existence, especially that a $\mathrm{C}=\mathrm{O}$ stretching is most likely to be in the compound. The FTIR spectrum showed the functional groups that are present in the activated carbon-based on Aloe. Even though the functional groups are not sharply confirmed or abundant, this compound still has some functional groups that could play a major role in its adsorption process.

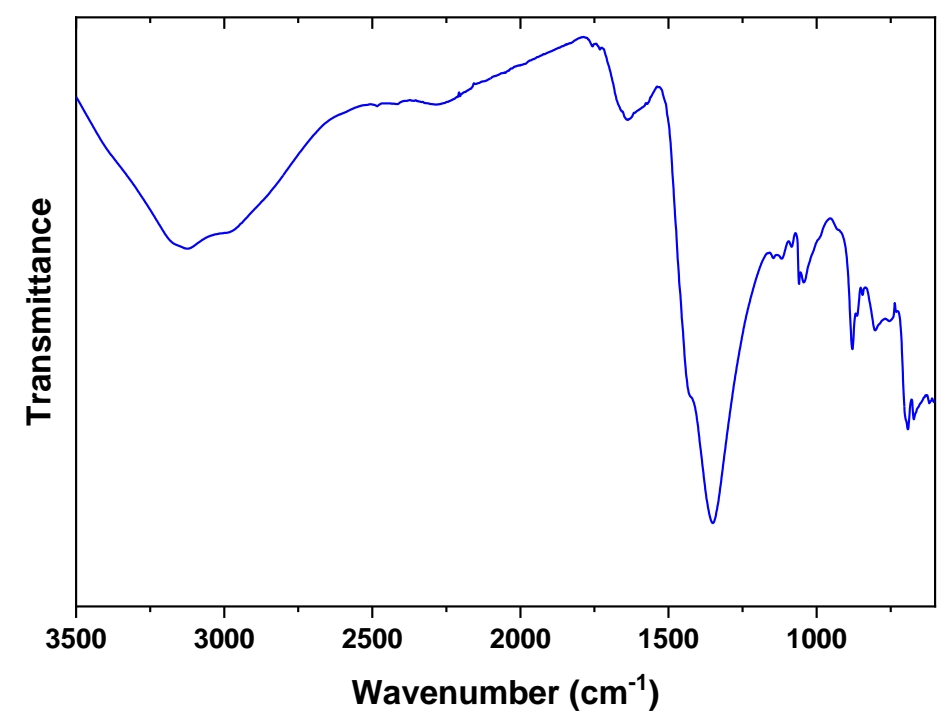

Figure 2. FTIR spectrum of the synthesized activated carbon.

\subsubsection{BET analysis.}

In order to determine the surface area of the newly synthesized activated carbon based on Aloe vera, a small sample of the compound have been subjected to BET testing where a full adsorption analysis that is based on liquid nitrogen adsorption at a temperature of $77 \mathrm{~K}$ will be conducted. The results will be processed using NovaWin software. The surface area is a very important parameter when dealing with an adsorption experiment since it can provide valuable information on whether the material analyzed is fit for removal of the desired elements through sorption or not. In fact, the morphology of the shape of a material's surface is crucial to correctly assess the sorption results. An increase in the surface's roughness will increase the adsorption capacity of a certain material. Moreover, the surface area of a material is based on the pores present within the structure of the material; the more porous the structure is, the bigger the surface area since more channels are passing through the material hence increasing its surface structure and this is why it is important when evaluating the characteristics of certain material for sorption experiments to define its surface area. A sample weighing $0.0706 \mathrm{~g}$ of activated Aloe was introduced for analysis in order to determine the BET surface area of the compound, and the results showed by the software indicated that the surface area that was obtained for the activated Aloe was estimated to be around $26.83 \mathrm{~m}^{2} / \mathrm{g}$. The obtained value is a good indicator of the activated Aloe's sorption capabilities and shows that the structure of the synthesized compound in powder form is porous enough and worthy of being tested for sorption experiments that could yield good results.

\subsection{Absorption evalaution.}

The first part of the experiment deals with the results obtained from the swelling experiments conducted on poplar sawdust with deionized water, as stated before and described 
with details in the previous part. Figure 3 shows the graph representing the swelling of poplar sawdust concerning contact time ranging from 0 to $24 \mathrm{~h}$. According to the figure, it is clear that the swelling of poplar sawdust did not show a high value, with all the points evaluated recording low swelling; moreover, it was noticed that most of the points showed swelling at a stable rate of $0.001 \mathrm{~g} / \mathrm{g}$.

In addition, it can be observed from the graph that the average swelling capacity was reached within the first 5 minutes of the experiment and remained more or less stable regarding the rest of the contact times that were tested. This suggests that a contact time of 5 min can be considered the optimum time needed for the poplar sawdust to attain nearly its maximum swelling with deionized water. The swelling experiments were conducted in order to study the morphological structure of the poplar sawdust to determine its sorption capability in general; therefore, the experiment showed that the structure of poplar sawdust was indeed porous, explaining the deionized water that was held within the sawdust over time.

The swelling that was obtained is considered low, but this does not mean that the structure of the poplar sawdust that was used is not porous since the sorbate, in this case, was deionized water, which means that most of the ions were removed from the water; hence, there were no amounts of ions that could bind to the surface of the poplar sawdust and in turn, increase the swelling. Therefore, what can be concluded from this small experiment is that the structure of poplar sawdust does include pores. This structure could be porous enough to acquire other types of sorbents that are rich in ions with an acceptable sorption capacity.

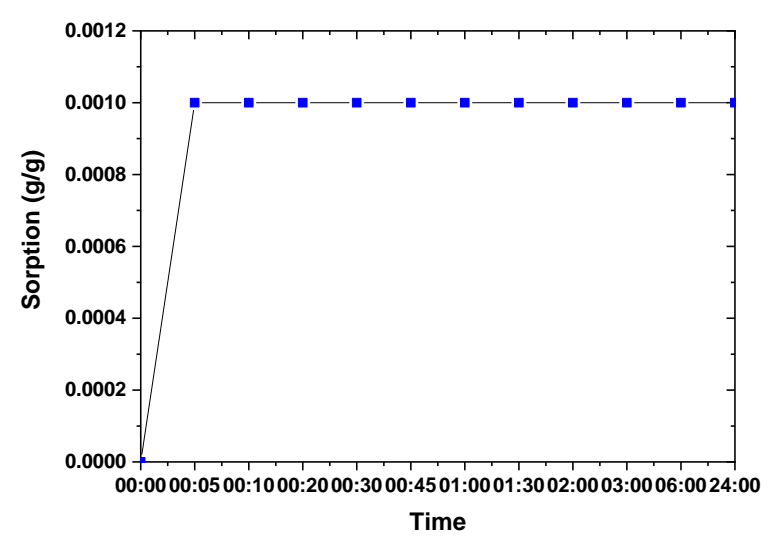

Figure 3. Swelling experiment of poplar sawdust.

Figure 4 represents the poplar sawdust's sorption capacity in the experiments concerning contact time and shows poplar sawdust's affinity towards diesel oil. It is important to note that the graph presented in this figure is actually based on the average of the three sorption trials that have been conducted between poplar sawdust and diesel oil where the average result between these three trials was taken into consideration for each specific contact time in order to build the following graph.

In a very similar behavior of poplar sawdust with deionized water, Figure 4 shows that poplar sawdust has behaved in nearly the same manner as in the case of the deionized water, which means that sawdust saw a rapid increase in sorption capacity within a very short period of time (5 min). This sorption capacity remains in a rigid way relatively stable throughout all the contact times that were tested, with sorption reaching approximately $0.08 \mathrm{~g} / \mathrm{g}$ in the first points of the experiments (until a time of 30 minutes is reached) after which the sorption 
capacity decreases within the contact times ranging from 30 minutes to 2 hours where it starts to increase again reaching a maximum value of $0.09 \mathrm{~g} / \mathrm{g}$ at a contact time of 24 hours.

The graph proves that the swelling experiments for poplar sawdust correctly predicted the poplar sawdust's behavior with a type of sorbent that is different from the deionized water. The swelling experiments gave a clear view of poplar sawdust's behavior with diesel oil in terms of the quick increase in the sorption capacity within a very short contact time and the stability of this sorption that was maintained throughout the different contact times. According to the graph represented by Figure 4, it can be shown that the sorption capacity of poplar sawdust by acquiring the diesel oil increases with the contact time, increasing at a rapid rate at first and within a short contact time, then decreasing slightly with contact time in order to decrease again after long contact times starting with 2 hours until 24 hours. The advantage that was presented by poplar sawdust is its affinity to attract diesel oil rapidly. It is normal to receive a sorption capacity by the sawdust into diesel that is higher than the sorption capacity that was recorded for sawdust with deionized water, and this is because the ions that are present within the diesel oil are much higher than the ions in the deionized water which naturally increases the affinity of sawdust and its structure towards diesel oil and hence increases the sorption capacity.

Moreover, poplar sawdust shows that the maximum sorption capacity it had with diesel oil was reached a maximum value of nearly $0.1 \mathrm{~g}$ per $1 \mathrm{~g}$ of sawdust; however, this value was reached in one day, and the duration of this period might be considered critical when dealing with oil spills so shorter durations are probably preferred. Therefore, it is safe to say that a small duration of contact between poplar sawdust and diesel oil is enough to reach the poplar sawdust's sorption capacity, especially that this sorption capacity increases very slightly after long periods of time.

Similar to the experiment of poplar sawdust with diesel oil, another one has been conducted to check the sorption of heating oil into the sawdust. As Figure 5 shows, the sorption capacity of heating oi into the poplar sawdust increases with the increase of contact time. A sharp increase in the sorption capacity is observed during only the first five minutes. It is safe to say that the sorption capacity progresses steadily with the different contact times by retaining a stable sorption capacity ranging from $0.04 \mathrm{~g} / \mathrm{g}$ to $0.043 \mathrm{~g} / \mathrm{g}$.

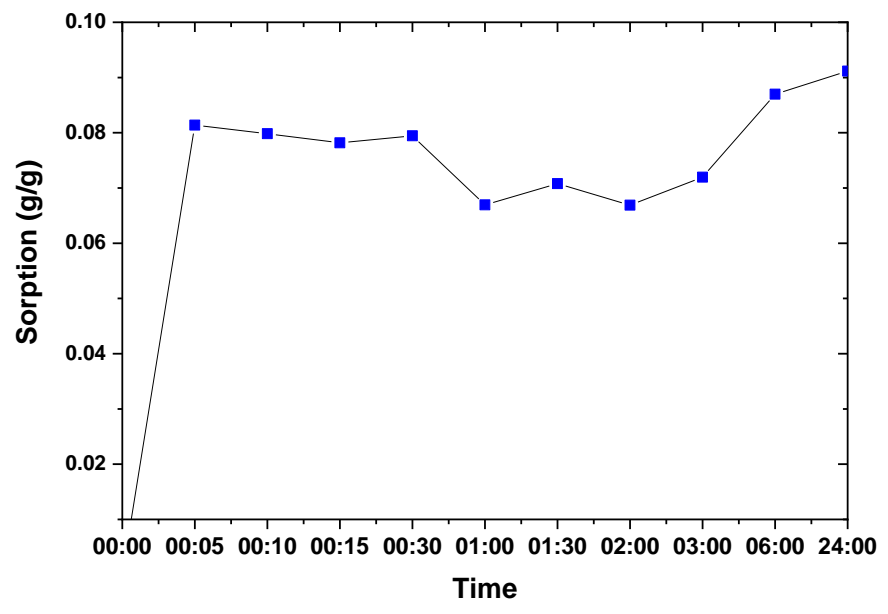

Figure 4. Adsorption of diesel oil on poplar sawdust.

After 24 hours of contact time, heating oil's sorption capacity into the sawdust reaches a maximal value of $0.45 \mathrm{~g} / \mathrm{g}$. Again, the graph shows that a contact time of 5 min can be 
considered an optimum time to recover nearly most heating oil amounts by the sawdust. The behavior of the poplar sawdust with heating oil is very similar to when diesel oil was introduced for sorption measurements into sawdust in the previous experiments since both graphs show a similar trend of a sharp and fast increase in sorption capacity during the first $5 \mathrm{~min}$ of the experiments after which the sorption capacity remains almost steady and experiences a slight increase towards the late contact times that were used in both of the experiments ( 6 hours and $24 \mathrm{~h})$.

The difference between both sorption experiments of the two types of tested oils (diesel and heating oil) can be clearly observed within the comparisons of their two respective graphs (Figures 4 and 5). The sorption capacity of heating oil into sawdust is relatively lower than the sorption of diesel oil into sawdust $(0.045 \mathrm{~g} / \mathrm{g}$ and $0.09 \mathrm{~g} / \mathrm{g}$, respectively), which means that the sawdust had more affinity to attract and extract diesel oil than heating oil at least in the contact times that were used. This could be explained by the fact that the heating oil that was used in the experiments is heavier than the diesel oil. When the oil is heavy, usually the sorption process takes a longer time, and equilibrium is reached in later stages. Also, since the diesel oil is a light oil, it is normal for the sorption into sawdust to happen fast since the molecules move faster than the molecules of the more viscous and heavy heating oil.

Since the heating oil is viscous and assuming that the morphological structure of poplar sawdust is similar in both the experiments with the two oils, then it is possible that the heating oil, while entering the structure of the sawdust has blocked some pores within the structures due to its higher viscosity than that of diesel oil and therefore has blocked some empty spaces where more oil could be filled, and this could explain why the sorption capacity of heating oil into sawdust was observed to be lower than the sorption capacity of diesel oil into the same sawdust. Nevertheless, sawdust still showed good sorption of heating oil even though the numbers were not very encouraging than the values obtained from the sorption experiments between diesel oil and poplar sawdust.

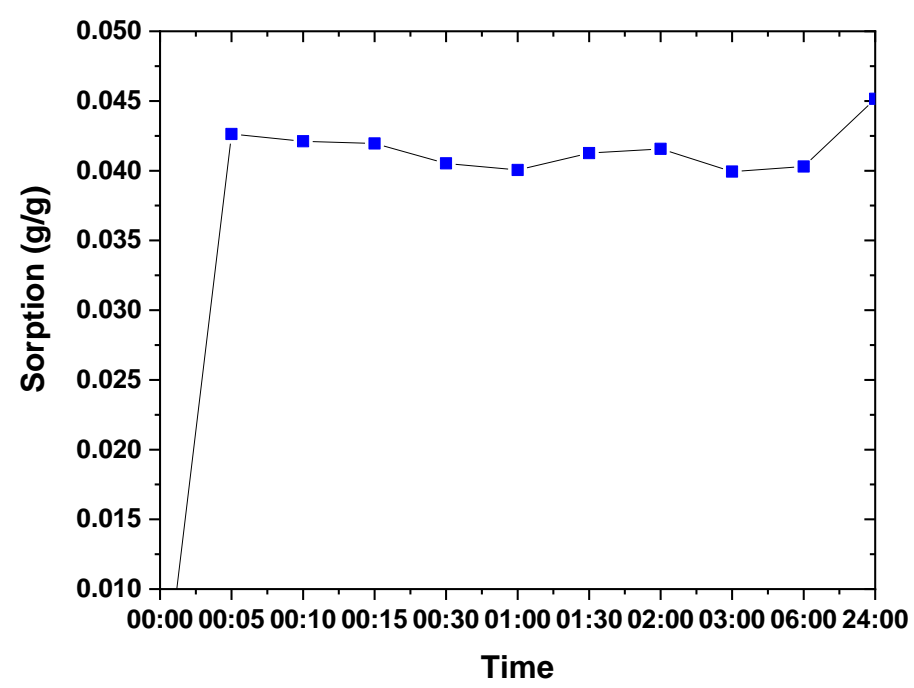

Figure 5. Adsorption of heating oil into poplar sawdust.

It is notable to mention that many previous work and research have dealt with the potential of sawdust in general, whether by using poplar sawdust or sawdust from other origins and doing further chemical enhancing of its structure. For instance, Šćiban et al. investigating the use of poplar sawdust as a cheap alternative for the removal of heavy metal ions from electroplating waters specifically the removal of cadmium, zinc and copper ions. The 
investigation consisted of an evaluation of the efficiency of removal of poplar sawdust of the mentioned heavy metals through a system of a single metal solution and a system of a multimetal solution while plotting several adsorption isotherms such as Langmuir and BET in order to check which isotherm fitted best the adsorption process of the experiment. The authors found that most of the adsorption isotherms that fitted corresponded to multilayer adsorption when dealing with a multi-metal solution, whereas the adsorption in a single-metal solution mostly showed the formation of a single layer. The adsorption results for the tested heavy metals showed that zinc ions had approximately the same adsorption rate for both systems. In contrast, cadmium ions were adsorbed well in the single-metal system and the copper ions in the multimetals system [30].

Beech sawdust was used in batch studies for adsorption purposes to study the removal of hexavalent chromium ions. It was found that the optimum $\mathrm{pH}$ to maximize the adsorption capacity was found to be equal to 1.0 with an optimum contact time of 1 hour and $20 \mathrm{~min}$. Moreover, the results showed that with increasing the metal concentration of hexavalent chromium in the solution, the adsorption capacity decreased, indicating that the adsorption capacity will increase with a small amount of metal concentration, after which the adsorption capacity decreases. Both Langmuir and Freundlich isotherms were found to fit the adsorption isotherm obtained by removing hexavalent chromium by the Beech sawdust [31].

A similar and more detailed study was performed by Baral et al. to remove hexavalent chromium, but this time using modified sawdust. The study was based on checking many parameters that would affect the adsorption process, such as the amounts of sawdust and chromium used, the $\mathrm{pH}$, the temperature, and the contact time, emphasizing the kinetic and thermodynamic studies. The study concluded that the adsorption process reached equilibrium after a contact time of 3 hours. It was found that the $\mathrm{pH}$ was greatly influential in the adsorption process as the adsorption capacity increased with the decrease of the $\mathrm{pH}$ where results showed that the optimum $\mathrm{pH}$ was found to be ranging between 4.5 and 6.5 based on an initial concentration of $5 \mathrm{mg} / \mathrm{L}$ for the hexavalent chromium. The thermodynamic parameters that were evaluated, such as the enthalpy and the Gibbs free energy, showed that the adsorption process was an exothermic reaction [32].

Using batch techniques, Yu et al. studied the adsorption of $\mathrm{Cu}(\mathrm{II})$ ions into maple sawdust by evaluating parameters similar to the ones studied by Baral et al., where it was found that adsorption might have been the main mechanism that was leading the binding of the copper ions into the surface of the maple sawdust without elimination of the ion exchange possibility and what's more, the $\mathrm{pH}$, initial concentration of the copper ions and the contact time were all parameters found to have an impact in shifting the adsorption process [33].

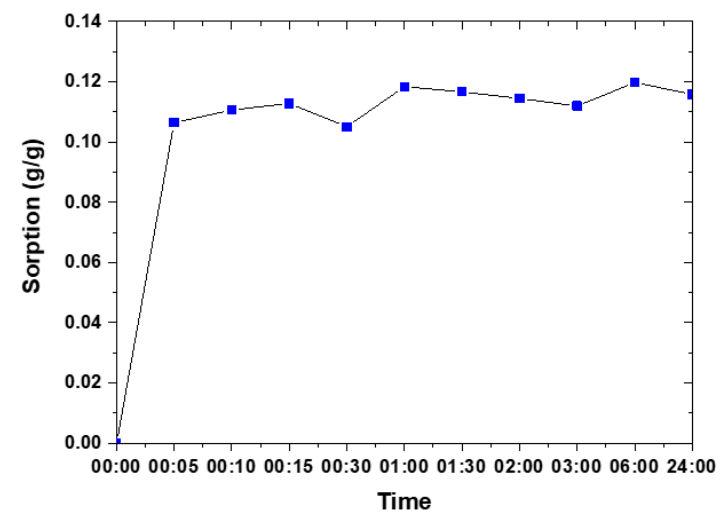

Figure 6. Adsorption of diesel oil into activated Aloe. 
Even though a good analysis was obtained from conducting the sorption experiments to evaluate the poplar sawdust and its sorption capacity towards diesel oil and heating, the main focus was given to the sorption experiments that will be conducted with the newly synthesized compound, which is a form of activated carbon-based on Aloe vera. The average result that was obtained from the sorption experiment of diesel oil into the activated carbon is shown in Figure 6.

According to the figure, when a certain amount of Aloe is in contact with the diesel oil, the observed sorption behavior is quite similar to the trend that emerged from the sorption of diesel into sawdust. Even when activated Aloe is introduced, the sorption capacity still increases with the contact time, especially during the initial contact time of 5 minutes, where the rise in the sorption capacity is rapid and sharp, shifting in just a short time from 0 to approximately $0.11 \mathrm{~g} / \mathrm{g}$. After the initial rise, the diesel oil's sorption capacity into the activated aloe experiences some form of stability until a contact time of 30 minutes is reached, where the sorption capacity elevates again to each its maximum recorded value of $0.12 \mathrm{~g} / \mathrm{g}$.

The value of the sorption capacity then slightly decreases to reach $0.11 \mathrm{~g} / \mathrm{g}$ for a contact time of 3 hours then reaches again its maximum value of $0.12 \mathrm{~g} / \mathrm{g}$ at 6 hours, where it remains relatively stable afterward; therefore, it is safe to say that most of the sorption occurred in the very first few minutes of the experiments with traces of diesel oil being attracted by the activated Aloe as the contact time increased and regarding the slight decrease in the sorption capacity that was observed after a contact time of one full day was used, this can be attributed to the fact that the equilibrium was reached earlier in this adsorption process. Some quantities of diesel oil have escaped the surface of the activated Aloe due to the desorption phase.

Figure 6 also shows that even though the maximum sorption capacity was reached in a matter of 30 minutes, the optimum contact time to be selected is probably still $5 \mathrm{~min}$ in order to effectively remove spilled oil in case of an accident. The adsorption process did yield acceptable results even though the activated Aloe was anticipated to have a better sorption result than the one that was obtained.

In comparison to the sorption experiments of diesel oil into the poplar sawdust, it is clear that the activated Aloe has an advantage as the better adsorbent for diesel oil if both products were to be compared with poplar sawdust achieving a sorption capacity of $0.08 \mathrm{~g} / \mathrm{g}$ in average in comparison to the $0.11 \mathrm{~g} / \mathrm{g}$ of the activated Aloe.

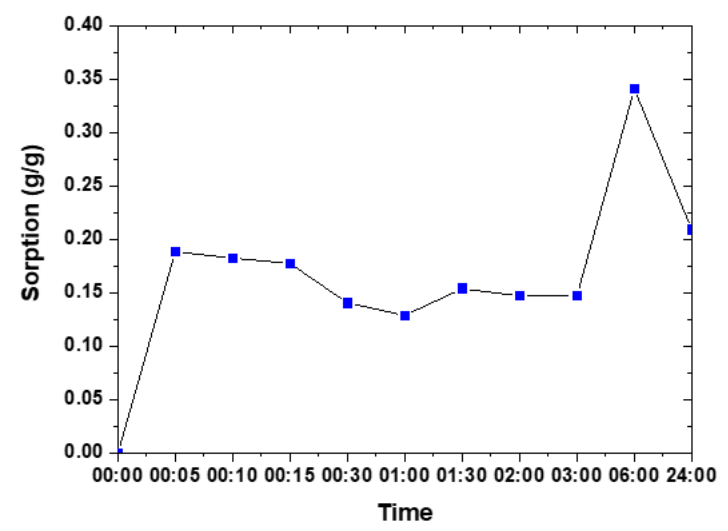

Figure 7. Adsorption of heating oil into activated carbon from Aloe vera.

This difference in the sorption capacity could be attributed to the actual structures of both the poplar sawdust and the activated Aloe; the activated carbon could have a better and more plain surface area and an increase in the porous structure than the sawdust due to surface 
modification, which explains the better sorption capacity of diesel into the synthesized activated Aloe in comparison with the sawdust. However, it is not a shock to get relatively low results for the activated Aloe with diesel oil. The synthesized product had an average surface area as shown by the characteristics conducted, which means that its ability to attract diesel oil will be lowered.

The results that were obtained from the sorption experiment of heating oil into the activated Aloe are in a different situation as shown by Figure 7, which represents the sorption capacity of the activated Aloe with heating oil concerning contact time. Again, in this experiment, the trend remained identical to all the previous trends observed in the other experiments, with the sorption capacity increasing with the increase of contact time. However, the interesting part that can be clearly noticed from the graph is that the sorption capacities acquired by this experiment have the largest values indisputably in comparison with the rest of the experiments (both sawdust with diesel and heating oils and activated Aloe with diesel oil).

According to Figure 7, the sorption capacity increases steadily and sharply in the very first few minutes. It attains a value of $0.2 \mathrm{~g} / \mathrm{g}$, after which the sorption capacity experiences slight and negligible changes (both increases and decreases) ranging between $0.14 \mathrm{~g} / \mathrm{g}$ and 0.16 $\mathrm{g} / \mathrm{g}$ throughout the progression of the contact time until a value of $0.35 \mathrm{~g} / \mathrm{g}$ of the sorption capacity is reached at a contact time of 6 hours. This value decreases dramatically to reach a value of $0.2 \mathrm{~g} / \mathrm{g}$ when a contact time of 1 day is reached. This decrease observed between the final two tested points could be attributed to the fact that the equilibrium was reached between the contact times of 6 hours and 24 hours, where the desorption cycle led to this decrease in the sorption capacity.

Therefore it is safe to say that although a good sorption capacity has been acquired in a very short amount of contact time, the optimum contact time to attract the possible quantity of heating oil was found to be 6 hours. This value is still acceptable if it were to be considered for a cleanup application. In general, the sorption experiments that were conducted between heating oil and the activated Aloe proved to have good results; if all the results are to be compared, it is noticed that the reaction of activated Aloe towards the heating oil was much better than for the diesel oil with maximum adsorption capacities of $0.35 \mathrm{~g} / \mathrm{g}$ and $0.12 \mathrm{~g} / \mathrm{g}$ respectively.

These results can only conclude that the synthesized activated carbon's affinity towards the heating oil was much better than for diesel oil. In terms of properties of the oils used, the activated Aloe showed a better affinity towards the heavier and more viscous oil rather than the light oil, which is proved by the fact that the activated Aloe was able to attract amounts of heating oil reaching up to $0.35 \mathrm{~g} / \mathrm{g}$ of its adsorption capacity. Moreover, it is noticed that the activated Aloe showed much better results for adsorption of heating oil than the results shown by poplar sawdust $(0.35 \mathrm{~g} / \mathrm{g}$ and $0.045 \mathrm{~g} / \mathrm{g}$ respectively) and taking into consideration that sawdust is a serious contender and applicant for the removal of oil from water then this outcome proves that the activated Aloe that was synthesized or at least an activated carbon-based on Aloe vera, in general, should be considered for oil sorption and its removal from water in applications of oil spill cleanups at least when dealing with heavy oils.

Many studies have been based on the sorption capabilities of Aloe vera. However, the majority of these studies did not get involved with oil experiments and focused on other adsorption processes such as the removal of heavy metals by materials based on aloe [34-38], dyes [39-42], and fluoride removal [43-45] among many other applications. 
Cortez et al. conducted a study of oil sorption into Aloe vera since Aloe was highly abundant and cheap in Mexico. The contact angle measurement showed that Aloe was considered hydrophobic as the contact angle exceeding $90^{\circ}$. The experiments consisted of testing three different types of plants. However, regarding the focus on Aloe, it was studied in both raw and modified forms. The sorption results on raw Aloe vera showed good sorption characteristics as the raw Aloe was able to reach a good sorption capacity of $9 \mathrm{~g} / \mathrm{g}$. This value decreased when multi-walled carbon nanotubes composites were introduced to the Aloe to reach a value of $7.8 \mathrm{~g} / \mathrm{g}$ and decreased further to $7.3 \mathrm{~g} / \mathrm{g}$ when Aloe was treated with carbon nanotubes and $\mathrm{Fe}$ (III) oxide. Coating the Aloe with polystyrene and treatment with $\mathrm{SiO}_{2}$ particles resulted in a sorption capacity of $5.8 \mathrm{~g} / \mathrm{g}$ for Aloe, and when the treatment involved the addition of $\mathrm{Fe}$ (III) oxide, the sorption capacity increased to reach its highest value of $9 \mathrm{~g} / \mathrm{g}$ [17].

\section{Conclusions}

Oil-spills still have a chance of occurrence and could result from many causes such as rig blowouts and tanker accidents. These incidents proved extremely detrimental as they claimed human lives and even affected plants and animals in both the short and long terms. Therefore, an interest in protecting the environment from these potential threats grew up quickly. Many studies and researches focused on finding a way to contain the oil spill after the incident and remove it to clean up the environment from the oily wastes.

Usually, the cleanup methods applied are mostly physically applied, such as skimmers and in situ burning, but the studies were more focused on the use of chemical applications that could be deployed to remove the spilled oil. One of the major chemicals used nowadays is dispersants. Many studies focused on using alternative chemical compounds to remove oil spilled from the environment; activated carbon was of high interest due to its high sorption abilities; however, this material posed different drawbacks in terms of reusability and selectiveness, and cost. Hence, studies shifted their focus towards cheaper materials such as agricultural wastes in order to test their sorption capabilities and their potential for oil-spill cleanup.

In this work, poplar sawdust and activated carbon-based on Aloe vera were subjected to adsorption experiments using two different oil types: diesel oil and heating oil. The purpose was to check how both compounds would behave in the presence of oil with certain characteristics and whether they can be considered for future oil removal. Starting with poplar sawdust, swelling experiments were conducted with the use of deionized water in order to obtain a clear view of the behavior of poplar sawdust in an adsorption process. This step proved to be correct as the exact behavior was predicted for the adsorption of both diesel and heating oils into the poplar sawdust with the sawdust achieving a better sorption result for diesel oil than heating oil and this could be due to the viscosities of the oils as the lightest oil would achieve better adsorption into the sawdust since the heating oil which is more viscous than diesel could move slowly within the pores of sawdust thus blocking the passage for additional sorption.

The main focus was to check the newly synthesized compound's adsorption capabilities and, therefore, since activated carbon based on Aloe vera was synthesized using specific recipes and guidelines. After synthesizing the desired material, the activated carbon was to be processed through characterization followed by sorption experiments. The characterization part consisted first of evaluating the BET surface area, which indicates that the activated Aloe 
possessed a good surface area fit for adsorption. FTIR analysis showed via the spectrum that the activated Aloe could have some potential functional groups that are important for the adsorption potential of the synthesized compound. The sorption experiments of diesel oil into the activated Aloe showed that the results obtained were better than the sorption capacity that was obtained from the removal of diesel oil by the poplar sawdust.

Moreover, the results were totally different when the heating oil was adsorbed into the activated Aloe. The results obtained were the highest values recorded between the four sorption case studies. All the experiments conducted showed that the poplar sawdust is a good adsorbent for the types of oils used. More importantly, the characterization process showed that the activated carbon that was based on Aloe vera showed good sorption characteristics. Adsorption experiments proved that the activated Aloe is a good candidate for oils' adsorption, especially the more viscous oils.

Though promising in terms of removal of oil-spills, the synthesized material is still novel and more studies should be considered to check the sorption capacity of this material for other types of oils. Also, more parameters should be taken into accounts, such as the effect of $\mathrm{pH}$, agitation rate, and contact time, among others, and their role in the adsorption process. The compound's morphological structure could easily be enhanced and changed even through a change in the recipe or further modifications. The whole experiment proved that the activated Aloe is a good sorbent and has a good potential to be used in future applications. Further research is needed to improve its candidacy as an applicant for oil-spill removal.

\section{Funding}

This work was financed by the project of Kavala Port S.A. "assessment and measures of microplastics pollution in the marine environment of Kavala region" (acronym: MICROPLAKA; project code: 30344).

\section{Acknowledgments}

This research has no acknowledgment.

\section{Conflicts of Interest}

The authors declare no conflict of interest.

\section{References}

1. de la Huz, R.; Lastra, M.; López, J. Oil Spills. In: Encyclopedia of Environmental Health. Nriagu, J.O. Ed. Elsevier: Burlington, 2011; pp 251-255.

2. Helmore, E. Deepwater Horizon disaster had much worse impact than believed, study finds. The Guradian 2020, https://www.theguardian.com/environment/2020/feb/13/deepwater-horizon-disaster-oil-worseimpact-study-finds, access date 13-Feb-2020.

3. Kyzas, G.Z.; Matis, K.A. Nanoadsorbents for pollutants removal: A review. Journal of Molecular Liquids 2015, 203, 159-168, https://doi.org/10.1016/j.molliq.2015.01.004.

4. Deliyanni, E.A.; Kyzas, G.Z.; Triantafyllidis, K.S.; Matis, K.A. Activated carbons for the removal of heavy metal ions: A systematic review of recent literature focused on lead and arsenic ions. Open Chemistry 2015, 13, 699-708, https://doi.org/10.1515/chem-2015-0087.

5. Paulauskiene, T. Ecologically friendly ways to clean up oil spills in harbor water areas: crude oil and diesel sorption behavior of natural sorbents. Environmental Science and Pollution Research 2018, 25, 9981-9991, https://doi.org/10.1007/s11356-018-1316-8.

6. Zouboulis, A.I.; Avranas, A. Treatment of oil-in-water emulsions by coagulation and dissolved-air flotation. Colloids and Surfaces A: Physicochemical and Engineering Aspects 2000, 172, 153-161, https://doi.org/10.1016/S0927-7757(00)00561-6. 
7. Matis, K.A.; Zouboulis, A.I. Electrolytic flotation: an unconventional technique. In: Flotation Science and Engineering. Matis, K.A. Ed. Marcel Dekker: New York, USA, 1995; pp 385-413.

8. Baharuddin, S.H.; Mustahil, N.A.; Reddy, A.V.B.; Abdullah, A.A.; Mutalib, M.I.A.; Moniruzzaman, M. Development, formulation and optimization of a novel biocompatible ionic liquids dispersant for the effective oil spill remediation. https://doi.org/10.1016/j.chemosphere.2020.126125.

9. Apostolopoulos, G.; Fardis, M.; Chandrinou, C.; Giannakopoulos, K.; Bidikoudi, M.; Boukos, N.; Falaras, P.; Batzias, F.; Sidiras, D.; Siontorou, C. Experimental Design of Laboratory Measurements for Hydrocarbons, Salts and Dyes Adsorption on Modified Lignocellulosic Materials in Aquatic Media. Chemical Engineering Transactions 2014, 39.

10. Navarathna, C.M.; Bombuwala Dewage, N.; Keeton, C.; Pennisson, J.; Henderson, R.; Lashley, B.; Zhang, X.; Hassan, E.B.; Perez, F.; Mohan, D.; Pittman, C.U.; Mlsna, T. Biochar Adsorbents with Enhanced Hydrophobicity for Oil Spill Removal. ACS Applied Materials \& Interfaces 2020, 12, 9248-9260, https://doi.org/10.1021/acsami.9b20924.

11. Oliveira, L.M.T.M.; Oliveira, L.F.A.M.; Sonsin, A.F.; Duarte, J.L.S.; Soletti, J.I.; Fonseca, E.J.S.; Ribeiro, L.M.O.; Meili, L. Ultrafast diesel oil spill removal by fibers from silk-cotton tree: Characterization and sorption potential evaluation. Journal of Cleaner Production 2020, 263, https://doi.org/10.1016/j.jclepro.2020.121448.

12. Omer, A.; Khalifa, R.; Tamer, T.; Alsayed, A.; Ammar, Y.; Mohy Eldin, M. Kinetic and thermodynamic studies for the sorptive removal of crude oil spills using a low-cost chitosan-poly (butyl acrylate) grafted copolymer. Desalination and water treatment 2020, 192, 213-225, https://doi.org/10.5004/dwt.2020.25704.

13. Paulauskiene, T.; Uebe, J.; Karasu, A.U.; Anne, O. Investigation of Cellulose-Based Aerogels for Oil Spill Removal. Water, Air, \& Soil Pollution 2020, 231, https://doi.org/10.1007/s11270-020-04799-1.

14. Raza, R.; Panja, A.; Ghosh, K. Diaminomaleonitrile-functionalized gelators in F-/CN- sensing, phaseselective gelation, oil spill recovery and dye removal from water. New Journal of Chemistry 2020, 44, 1027510285, https://doi.org/10.1039/D0NJ01992E.

15. Wolok, E.; Barafi, J.; Joshi, N.; Girimonte, R.; Chakraborty, S. Study of bio-materials for removal of the oil spill. Arabian Journal of Geosciences 2020, 13, https://doi.org/10.1007/s12517-020-06244-3.

16. Wang, Z.; Barford, J.P.; Hui, C.W.; McKay, G. Kinetic and equilibrium studies of hydrophilic and hydrophobic rice husk cellulosic fibers used as oil spill sorbents. Chemical Engineering Journal 2015, 281, 961-969, https://doi.org/10.1016/j.cej.2015.07.002.

17. Acevedo Cortez, J.S.; Kharisov, B.I.; Serrano, T.; González, L.T.; Kharissova, O.V. Hydrophobization and evaluation of absorption capacity of Aloe vera, Opuntia ficus-indica and Gelidium for oil spill cleanup. Journal of Dispersion Science and Technology 2019, 40, 884-891, https://doi.org/10.1080/01932691.2018.1488593.

18. El-Azazy, M.; Dimassi, S.N.; El-Shafie, A.S.; Issa, A.A. Bio-Waste Aloe vera Leaves as an Efficient Adsorbent for Titan Yellow from Wastewater: Structuring of a Novel Adsorbent Using Plackett-Burman Factorial Design. Applied Sciences 2019, 9, https://doi.org/10.3390/app9224856.

19. Kyzas, G.; Fu, J.; Matis, K. New Biosorbent Materials: Selectivity and Bioengineering Insights. Processes 2014, 2, 419-440, https://doi.org/10.3390/pr2020419.

20. Rápó, E.; Aradi, L.E.; Szabó, Á.; Posta, K.; Szép, R.; Tonk, S. Adsorption of Remazol Brilliant Violet-5R Textile Dye from Aqueous Solutions by Using Eggshell Waste Biosorbent. Scientific Reports 2020, 10, https://doi.org/10.1038/s41598-020-65334-0.

21. Shaikhiev, I.G.; Kraysman, N.V.; Sverguzova, S.V.; Spesivtseva, S.E.; Yarothckina, A.N. Fish scales as a biosorbent of pollutants from wastewaters and natural waters (A literature review). Biointerface Research in Applied Chemistry 2020, 10, 6893-6905.

22. Mwandira, W.; Nakashima, K.; Togo, Y.; Sato, T.; Kawasaki, S. Cellulose-metallothionein biosorbent for removal of $\mathrm{Pb}(\mathrm{II})$ and $\mathrm{Zn}$ (II) from polluted water. Chemosphere 2020, 246, https://doi.org/10.1016/j.chemosphere.2019.125733.

23. Pan, J.; Gao, B.; Song, W.; Xu, X.; Yue, Q. Modified biogas residues as an eco-friendly and easilyrecoverable biosorbent for nitrate and phosphate removals from surface water. Journal of Hazardous Materials 2020, 382, https://doi.org/10.1016/j.jhazmat.2019.121073.

24. Semião, M.A.; Haminiuk, C.W.I.; Maciel, G.M. Residual diatomaceous earth as a potential and cost effective biosorbent of the azo textile dye Reactive Blue 160. Journal of Environmental Chemical Engineering 2020, 8, https://doi.org/10.1016/j.jece.2019.103617.

25. Xu, S.; Xing, Y.; Liu, S.; Hao, X.; Chen, W.; Huang, Q. Characterization of Cd(2+) biosorption by Pseudomonas sp. strain 375, a novel biosorbent isolated from soil polluted with heavy metals in Southern China. Chemosphere 2020, 240, https://doi.org/10.1016/j.chemosphere.2019.124893.

26. Zang, D.; Liu, F.; Zhang, M.; Gao, Z.; Wang, C. Novel superhydrophobic and superoleophilic sawdust as a selective oil sorbent for oil spill cleanup. Chemical Engineering Research and Design 2015, 102, 34-41, https://doi.org/10.1016/j.cherd.2015.06.014. 
27. Ismail, A.S.; El-Sheshtawy, H.S.; Khalil, N.M. Bioremediation process of oil spill using fatty-lignocellulose sawdust and its enhancement effect. Egyptian Journal of Petroleum 2019, 28, 205-211, https://doi.org/10.1016/j.ejpe.2019.03.002.

28. Shin, Y.; Winder, E.M.; Han, K.S.; Lee, H.; Bonheyo, G.T. Enhanced Capacities of Mixed Fatty AcidModified Sawdust Aggregators for Remediation of Crude Oil Spill. ACS Omega 2019, 4, 412-420, https://doi.org/10.1021/acsomega.8b02293.

29. da Costa Cunha, G.; Pinho, N.C.; Alves Silva, I.A.; Santos Silva, L.; Santana Costa, J.A.; da Silva, C.M.P.; Romão, L.P.C. Removal of heavy crude oil from water surfaces using a magnetic inorganic-organic hybrid powder and membrane system. Journal of Environmental Management 2019, 247, 9-18, https://doi.org/10.1016/j.jenvman.2019.06.050.

30. Šćiban, M.; Radetić, B.; Kevrešan, Ž.; Klašnja, M. Adsorption of heavy metals from electroplating wastewater by wood sawdust. Bioresource Technology 2007, 98, 402-409, https://doi.org/10.1016/j.biortech.2005.12.014.

31. Acar, F.N.; Malkoc, E. The removal of chromium(VI) from aqueous solutions by Fagus orientalis L. Bioresource Technology 2004, 94, 13-15, https://doi.org/10.1016/j.biortech.2003.10.032.

32. Baral, S.S.; Das, S.N.; Rath, P. Hexavalent chromium removal from aqueous solution by adsorption on treated sawdust. Biochemical Engineering Journal 2006, 31, 216-222, https://doi.org/10.1016/j.bej.2006.08.003.

33. Yu, B.; Zhang, Y.; Shukla, A.; Shukla, S.S.; Dorris, K.L. The removal of heavy metal from aqueous solutions by sawdust adsorption — removal of copper. Journal of Hazardous Materials 2000, 80, 33-42, https://doi.org/10.1016/S0304-3894(00)00278-8.

34. Beigzadeh, P.; Moeinpour, F. Fast and efficient removal of silver (I) from aqueous solutions using aloe vera shell ash supported Ni0.5Zn0.5Fe2O4 magnetic nanoparticles. Transactions of Nonferrous Metals Society of China 2016, 26, 2238-2246, https://doi.org/10.1016/S1003-6326(16)64341-8.

35. Moosa, A.; Ridha, A.; Hussien, N. Adsorptive Removal of Lead Ions from Aqueous Solution Using Biosorbent and Carbon Nanotubes. American Journal of Materials Science 2016, 2016, 115-124.

36. Moosa, A.; Ridha, A.; Hussien, N. Removal of Zinc Ions from Aqueous Solution by Bioadsorbents and CNTs. American Journal of Materials Science 2016, 2016, 105-114.

37. Giannakoudakis, D.A.; Hosseini-Bandegharaei, A.; Tsafrakidou, P.; Triantafyllidis, K.S.; Kornaros, M.; Anastopoulos, I. Aloe vera waste biomass-based adsorbents for the removal of aquatic pollutants: A review. Journal of Environmental Management 2018, 227, 354-364, https://doi.org/10.1016/j.jenvman.2018.08.064.

38. Abedi, S.; Zavvar Mousavi, H.; Asghari, A. Investigation of heavy metal ions adsorption by magnetically modified aloe vera leaves ash based on equilibrium, kinetic and thermodynamic studies. Desalination and Water Treatment 2016, 57, 13747-13759, https://doi.org/10.1080/19443994.2015.1060536.

39. Khaniabadi, Y.O.; Heydari, R.; Nourmoradi, H.; Basiri, H.; Basiri, H. Low-cost sorbent for the removal of aniline and methyl orange from liquid-phase: Aloe Vera leaves wastes. Journal of the Taiwan Institute of Chemical Engineers 2016, 68, 90-98, https://doi.org/10.1016/j.jtice.2016.09.025.

40. Omidi Khaniabadi, Y.; Mohammadi, M.; Shegerd, M.; Sadeghi, S.; Saeedi, S.; Basiri, H. Removal of Congo red dye from aqueous solutions by a low-cost adsorbent: activated carbon prepared from Aloe vera leaves shell. Environmental Health Engineering and Management Journal 2017, 4, 29-35, https://doi.org/10.15171/EHEM.2017.05.

41. Arivoli, S.; Sundaravadivelu, M.; Elango, K. Removal of basic and acidic dyes from aqueous solution by adsorption on a low cost activated carbon: Kinetic and thermodynamic study. Indian Journal of Chemical Technology 2008, 15. 130-139.

42. Malakootian, M.; Jafari Mansoorian, H.; Yari, A.R. Removal of reactive dyes from aqueous solutions by a non-conventional and low cost agricultural waste: adsorption on ash of Aloe Vera plant. J Iranian Journal of Health, Safety and Environment 2014, 2014.

43. Rayappan, S.; Jeyaprabha, B.; Prakash, P. A study on removal of fluoride ions using Aloe Barbadensis as a low-cost natural adsorbent. Journal of Applicable Chemistry 2014, 3, 1189-1201.

44. Murugan, M.; Subramanian, E. Application of Aloe Vera (Indian Aloe) - A plant material for defluoridation. Indian Journal of Environmental Protection 2002, 22, 1034-1039.

45. Shyam, R.; Kalwania, G.S. Removal of Fluorides in Drinking Water by Aloe Vera and Calcium Chloride. Chem Sci Trans. 2014, 3, 29-36. 